Fourth International Conference on Sustainable Construction Materials and Technologies http://www.claisse.info/Proceedings.htm

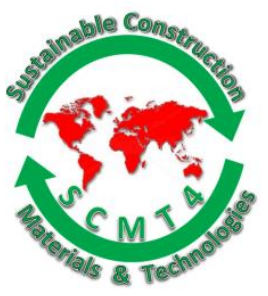

SCMT4

Las Vegas, USA, August 7-11, 2016

\title{
Long-Term Properties of Special Concrete with Natural Additive
}

\author{
Jaroslava Kot’átková ${ }^{1 a}$, and Pavel Reiterman ${ }^{1 b}$ \\ ${ }^{1}$ Experimental Centre; Czech Technical University in Prague, Thakurova 7, 16629, Prague, Czech \\ Republic. ${ }^{1 a}$ Email: <jaroslava.kotatkova@fsv.cvut.cz>, ${ }^{1 b}$ Email: 〈pavel.reiterman@fsv.cvut.cz〉.
}

\begin{abstract}
Present paper deals with the experimental study of high strength concrete with natural pozzolanic addition applied as Portland cement replacement. The motivation was to develop new type of high strength concrete with further application of environmental friendly materials. Natural pozzolans are silica-aluminous rocks which were successfully used in the ancient Rome as a component of hydraulic lime. Its high and regular porosity determines practical utilization as an adsorbent or filter agent. Performed experimental program is focused on the influence of natural pozzolan to the long-term properties. Studied additive was dosed as Portland cement replacement in doses of $10 \%, 30 \%$ and $50 \%$ by weight. Evaluation of developed high strength concrete mixtures was realized on the base of determination of the bulk density, flexural strength, compressive strength, water absorption coefficient and de-icing salts resistance. The above named properties were investigated at the age of 28,90 and 180 days. Gradual pozzolanic reaction caused expected increase of compressive strength of all studied mixtures. The highest increase by $25 \%$ exhibited mixture with $10 \%$ substitution. Concrete mixtures with higher cement substitution did not reach the properties of reference mixture. Water absorption coefficient values were negatively affected by the relatively high doses of studied additive of high porosity, but after 150 freeze-thaw cycles where not observed any deterioration of all studied mixtures. Based on the realized experimental program can be concluded the positive influence of natural pozzolan to long-term properties but its efficiency is very low. Substitution of Portland cement higher than $10 \%$ by weight generally reduced mechanical properties below the level of reference mixture.
\end{abstract}

\section{INTRODUCTION}

In traditional concrete industry there are numerous solutions to produce concrete with higher mechanical and durability properties. Common ways are the optimization of aggregates granularity and low level of w/c. Mentioned approaches cause low workability of fresh concrete. Modern high performance concretes (HPC) are usually conceive as micro-concrete, i.e. mixtures with $\mathrm{D}_{\max }$ up to $1 \mathrm{~mm}$. It is due to application of fibers reinforcing concrete matrix in order to get higher ductility. The term of HPC usually includes concretes with compressive strength higher than $60.0 \mathrm{MPa}$, in the case of UHPC were strength limit established to 150.0 MPa [Holcapek et al. 2014; Sovják et al. 2013; Reiterman et al. 2014]. For some types of loading is already unsuitable to use thin-walled elements, primarily in case of shear stress and dynamic loading [Holčapek et al. 2014]. That is why structures made of HPC and UHPC are presented especially by facing boards or bridge slab. Using of HPC and UHPC is often presented as friendly to raw material utilization. General savings of raw materials are timed by longer lifetime of structures made of HPC and 
maintenance cost [Sovják et al. 2013]. Besides to the high mechanical properties offer mentioned special concretes a good durability ensured by low w/c and high amount of active additives. The use of silica fume is convenient because of its high reactivity, which is enhanced by its high surface area. Silica fume improves both mechanical and durability properties of HPC, but its low availability results in high cost and therefore its utilization is limited to low amounts.

Durability properties are of high importance for high performance concrete as they determine the lifetime and serviceability of the construction. Many degrading factors are connected with the permeability of the material [Ahmadi and Shekarchi 2010; Reiterman et al. 2014]. However, the manufacture of concrete reaching high strength and featuring long durability requires a special approach to the design process of the material composition, which involves the need to use high amount of cement. This lead to the rise in cost, the rise of the negative environmental impact of increased cement production and also brings along some negative impacts on the properties of concrete, such as higher shrinkage [Kolár et al. 2016]. Consequently, there is the need to use supplementary cementitious materials (SCM), i.e. materials, which take part in the hydration process and thus can substitute part of the cement amount.

Essential motivation for further use of SCM lies in the positive influence on the durability of cement based composites. Gradual reaction of Portlandit $\left(\mathrm{Ca}(\mathrm{OH})_{2}\right)$ with reactive pozzolanas reduces its amount in the concrete and originating C-S-H and C-A-H phases significantly reduce the permeability of concrete and its transport ability.

Transport properties of cement based materials have a principal impact on ability to resist attack of aggressive environment [Biczók 1972]. Decreased resistance to action of frost or de-icing salts of cement mortars is caused by accumulation of water and vapor [Máca et al. 2014; Pavlík et al. 2014] what has a negative effect of visual state of new and historical buildings. Reduction of water transport rate is often ensured by insulation or application of modifying additives and admixtures. In this case was confirmed positive influence of pozzolanic additives which application is ordered during reconstruction of historical buildings [Drdácký et al. 2013]. High volume of some pozzolanic additives negatively affects initial strength evolution [Bodnárová et al. 2014; Tydlitát et al. 2014]. Generally, application of active mineral additives increase long-term durability of cement based composites [Basheer et al. 2001; Reiterman et al. 2015].

Natural zeolite (NZ) is a volcanic rock with good pozzolanic properties. Its microstructure is highly porous, the pores are of similar sizes and regular, which makes natural zeolite a good molecular sieve; next to this, it has the ability to bind metal cations and molecules of water. Both these properties of NZ are among others utilized in building industry, e.g. as an antibacterial agent on walls, the bearer of anti-freezing admixture in concrete, for production of low-alkali cement, as a fluidizing agent etc. [Feng and Peng 2005]. The performance of $\mathrm{NZ}$ in concrete and its effect on the mechanical properties of concrete has been reported to be good [Sabet at al. 2013; Ahmadi and Shekarchi 2010; Valipour et al. 2013; Kot'átková et al. 2015].

The scope of present paper is to verify long-term resistance of HPC to action of freeze-thaw cycling with parallel attack of deicing salts. Examination of scaling resistance was complemented by measurement of mechanical properties and water sorption properties of studied HPC. Mixture design took into the consideration environmental aspect of developed mixtures because of application of SCM.

Performed tests were provided up to the age of 180 days due to slower course of pozzolanic hydration processes. This topic is important and actual with respect to application of cement-concrete cover in road and especially highway construction. Low permeability and high amount of pozzolanic additives could prevent alkali-silicate reaction (ASR) of aggregates as well [Reiterman et al. 2015]. Permeability is a principal property affecting final ability of material to resist attack of environment - durability. 


\section{EXPERIMENTAL INVESTIGATION}

Methods. Determination of resistance of concrete surface to deicing salts was investigated according to CSN EN 732326 - methodology C [CSN EN 73 1326]. Testing is consisting of cycle temperature loading of cylinder samples of average $150 \mathrm{~mm}$, which surface was covered by $3 \%$ solution of NaCl. Load cycle starts with frosting phase down to $-18{ }^{\circ} \mathrm{C}$ lasting three hours and then continue by defrosting period up to $5{ }^{\circ} \mathrm{C}$ for another three hours. In case of action of salts and frost is loaded surface gradually damaged and surface layer is lost into the salt solution in the form of surface waste. After each 25 cycles is testing interrupted and concrete waste is collected. Final amount of dried cumulative waste is expressed to unit area $\left(\mathrm{g} / \mathrm{m}^{2}\right)$. For transport structures is usually required waste up to $1000 \mathrm{~g} / \mathrm{m}^{2}$ after 100 loading cycles. Introduced methodology is often marked as scaling resistance. The above described test was performed only in the age of 90 days due to long-term duration of this testing.

Absorption was measured by using of cubic specimen of edge $100 \mathrm{~mm}$ which were partially wetted (just up to $5 \mathrm{~mm}$ ) into water basin. In selected time intervals was gravimetrically recorded grow of water mass absorbed into the hardened composite. Absorption coefficient $A\left(\mathrm{~g} / \mathrm{m}^{2} \mathrm{~s}^{1 / 2}\right)$ was calculated for 10 and 20 minutes for each mixture, where $i$ is cumulative mass of water $\left(\mathrm{g} / \mathrm{m}^{2}\right)$ and $t$ time $(\mathrm{s})$. The above described test presents very quick way of water capability assessment.

All studied mixtures were designed with the suitable workability. These were after the relevant time period subjected to the flexural strength test and on the left fragments the compressive strength test was accomplished. Both tests were carried with the use of the loading device EU 40. The testing was performed according to CSN EN 12390-3 and CSN EN 12390-5.

Materials. The chemical composition of used binders can be seen in Table 1 and the composition of investigated mixtures is presented in Table 2 . The main binder constituent is represented by cement CEM I $52.5 \mathrm{R}$. To achieve the parameters of HPC, silica fume was added in a constant amount of $140 \mathrm{~kg} / \mathrm{m}^{3}$. Cement was partly replaced from 10 to $50 \%$ by weight by natural zeolite. The used natural zeolite is of the clinoptilolite type and it is quarried in Slovakia.

Water to binder ratio was kept constantly low with the use of a superplasticizer. Silica aggregate in four fractions complemented with silica flour were chosen in order to gain a good granulometry of the mixture. Silica flour has the medium particle size just about $15 \cdot 10^{-3} \mathrm{~mm}$ and in the performed research was considered only as filler.

Table 1. Chemical Composition of Used Cement and Active Additives

\begin{tabular}{|c|c|c|c|}
\hline \multirow{2}{*}{ Component } & \multicolumn{3}{|c|}{ Amount (\%) } \\
\cline { 2 - 4 } & CEM I 52.5 R & Natural zeolite & Silica fume \\
\hline $\mathbf{S i O}_{2}$ & 18.5 & 74.7 & 95.9 \\
\hline $\mathbf{A l}_{\mathbf{2}} \mathbf{O}_{\mathbf{3}}$ & 6.4 & 15.4 & 1.0 \\
\hline $\mathbf{F e}_{\mathbf{2}} \mathbf{O}_{\mathbf{3}}$ & 2.4 & 1.6 & 0.2 \\
\hline $\mathbf{C a O}$ & 65.3 & 3.3 & 0.9 \\
\hline $\mathbf{M g O}$ & 1.0 & 0.7 & 0.7 \\
\hline $\mathbf{K}_{\mathbf{2}} \mathbf{O}$ & 1.2 & 3.5 & 0.2 \\
\hline $\mathbf{N a}_{2} \mathbf{O}$ & 0.3 & 0.6 & 0.0 \\
\hline $\mathbf{T i O}_{2}$ & 0.0 & 0.2 & 0.1 \\
\hline $\mathbf{S O}_{3}$ & 4.9 & 0.0 & \\
\hline
\end{tabular}


Table 2. Composition of Studied Mixtures $\left(\mathrm{kg} / \mathrm{m}^{3}\right)$

\begin{tabular}{|l|c|c|c|c|}
\hline \multirow{2}{*}{ Component } & \multicolumn{4}{|c|}{ Mixtures } \\
\cline { 2 - 4 } & REF & Z10 & Z30 & Z50 \\
\hline Silica aggreagate $0.1-0.6 \mathrm{~mm}$ & 415 & 415 & 415 & 415 \\
\hline Silica aggreagate $0.3-0.8 \mathrm{~mm}$ & 265 & 265 & 265 & 265 \\
\hline Silica aggreagate $0.6-1.2 \mathrm{~mm}$ & 207 & 207 & 207 & 207 \\
\hline Silica aggreagate 1-4 mm & 150 & 150 & 150 & 150 \\
\hline Silica flour & 140 & 140 & 140 & 140 \\
\hline Silica fume & 140 & 140 & 140 & 140 \\
\hline Superplasticizer & 28.3 & 28.3 & 28.3 & 28.3 \\
\hline CEM I 52.5 R & 618 & 556 & 433 & 309 \\
\hline Natural zeolite & 0 & 62 & 185 & 309 \\
\hline Water & 160 & 160 & 160 & 160 \\
\hline
\end{tabular}

\section{RESULTS AND DISCUSSIONS}

Following text presents results of measuring of compressive strength $\left(f_{c m}\right)$, flexural strength $\left(f_{t m}\right)$, bulk density, scaling resistance and sorption of all mixtures with different zeolite replacement. Final values of bulk density are continuously reduced with increasing zeolite replacement what is expectable result because of higher bulk density of used Portland cement. It is necessary to note that samples were kept in the common laboratory environment. Evolution of bulk density is shown in Fig. 1 where is obvious gradual loss of free water content in the testing mixtures. Increasing of bulk density of mixture Z50 is probably caused by the gradual course of pozzolanic reaction and by the faster loss of free water during initial phases of hydration - high volume SCM concrete often exhibited increased permeability [Kot’átková et al. 2015].

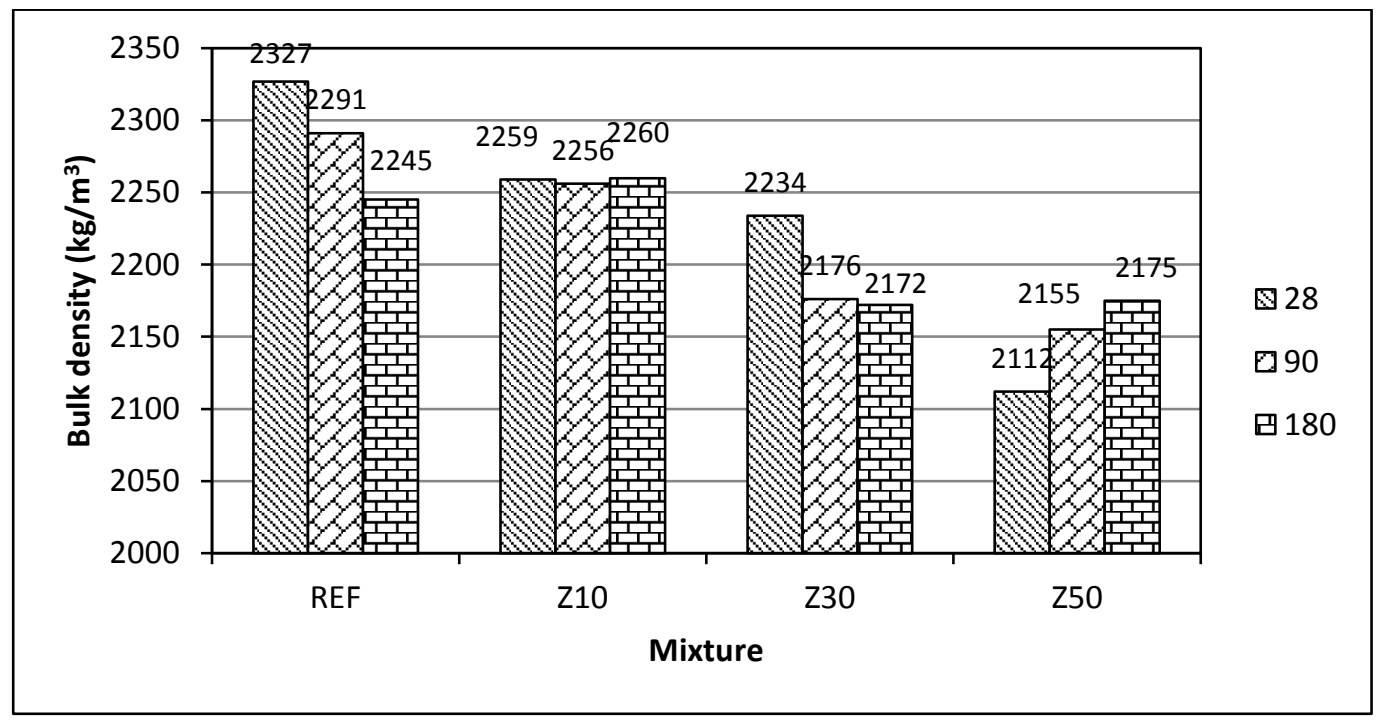

Figure 1. Evolution of Bulk Density in Time

Evolution of mechanical properties in time is shown in Fig. 2 and Fig. 3. The pozzolanic activity of silica fume (SF) is higher than that of natural zeolite, so the rise in compressive strength caused by SF comes 
earlier, and is followed by the strength increase due to the pozzolanic action of NZ. This compensation brings a rise increase of compressive strength for a long time period. The best values of compressive strength were achieved for the mixture containing $10 \%$ in weight of natural zeolite as substitution of cement, which were only slightly higher than for the reference mixture. With the rising content of NZ, the compressive strength went significantly down.

Evolution of flexural strength did not correspond with the results of the compressive strength. Similar trend was observed for other type of high volume SCM concrete mixtures and was explained by the expressive volume changes due to hydration processes what is accompanied with the micro-crack opening. Following pozzolanic reaction contributed to self-healing effect of studied mixtures [Bílek et al. 2015; Kolář et al. 2016].

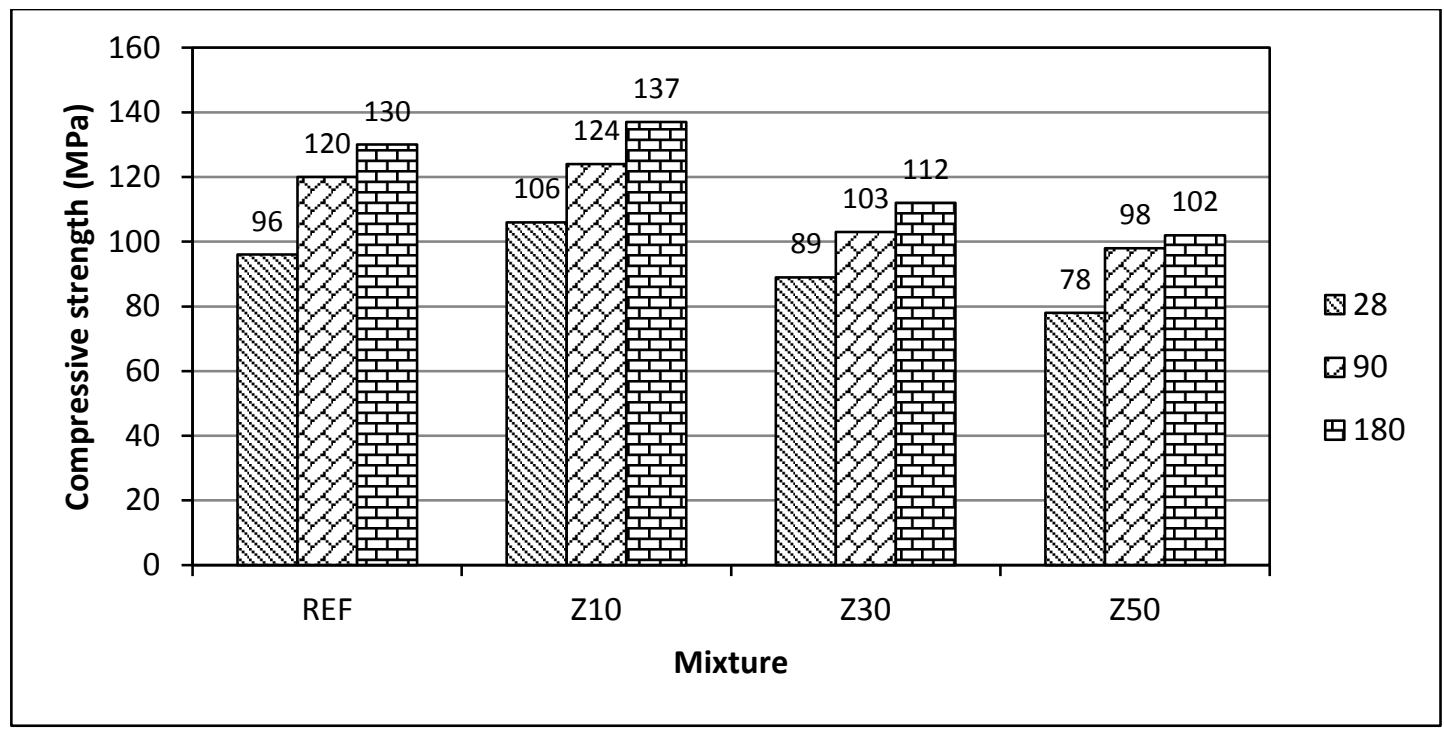

Figure 2. Evolution of Compressive Strength in Time

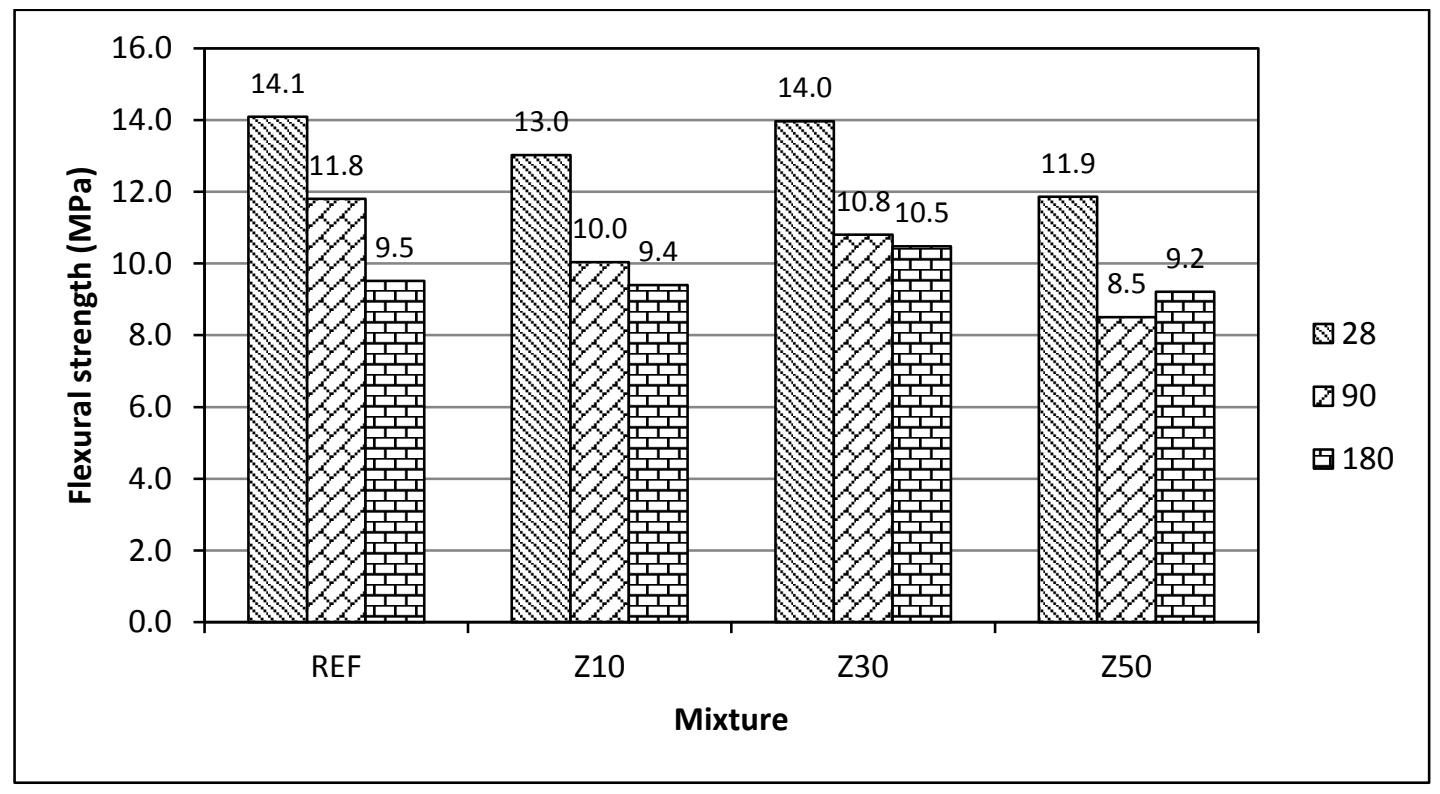

Figure 3. Evolution of Flexural Strength in Time 
For commonly used concrete in building industry is most frequently required maximum rate of scalling $1000 \mathrm{~g} / \mathrm{m}^{2}$ after 100 freeze-thaw cycles what was by obtained results highly passed because of no deterioration was observed. Freeze-thaw cycling measurement was accompanied by the determination of the adsorption coefficient which values are presented in Table 3.

Table 3. Adsorption coefficient

\begin{tabular}{|c|c|c|}
\hline \multirow{2}{*}{ Mixture } & \multicolumn{2}{|c|}{$\begin{array}{c}\text { Adsorption coefficient } \\
\left(\mathrm{g} / \mathrm{m}^{2} \mathrm{~s}^{1 / 2}\right)\end{array}$} \\
\cline { 2 - 3 } & 10 minutes & 20 minutes \\
\hline REF & 0.000612 & 0.000433 \\
\hline Z10 & 0.006325 & 0.004472 \\
\hline Z30 & 0.001237 & 0.001414 \\
\hline Z50 & 0.001512 & 0.001591 \\
\hline
\end{tabular}

\section{CONCLUSION}

This study was aimed at the evaluation of the effects of natural zeolite used as a supplementary cementitious material on the mechanical properties of high performance concrete and their development in time. The binder of the studied HPC was composed of three compounds - cement, silica fume and natural zeolite. NZ was dosed from $10-50 \%$ by weight as a substitution of cement. Application of silica fume and zeolite confirmed their good potential in HPC composition in relation to severe conditions exposure presented by freeze-thaw cycling. Thanks application of mineral additives was ensured excellent resistance of HPC already after 90 days. Results showed a decreasing trend in the compressive strength with the rising content of NZ, which was partly caused by the unreacted particles of NZ in concrete that did not take part in the pozzolanic reaction. These are very porous and increased the total porosity of concrete resulting in reduction of strength. The compressive strength rose even after 180 days from the manufacture of the samples, which is the proof of continuing pozzolanic reaction in long-term. Replacement of $10 \%$ of Portland cement seems to the optimal level of the natural zeolite application.

\section{ACKNOWLEDGEMENTS}

This research has been supported by the Czech Science Foundation, under project No. P105/12/G059.

\section{REFERENCES}

Ahmadi, B., and Shekarchi, M. (2010). "Use of Natural Zeolite as a Supplementary Cementitious Material." Cement and Concrete Composites, 32(2), 134-141.

Basheer, L., Kroop, J., and Cleland, D. J. (2001). "Assessment of the Durability of Concrete from its Permeation Properties: a review." Construction and Building Materials, 15, 93 - 103.

Biczók, I. (1972). “Concrete Corrosion and Concrete Protection”, Budapest, Akadémiai kiadó, 1972.

Bílek, V., Mec, P., Zidek, L., Moravec, T. (2015). "Concretes with Ternary Binders - Thinking about Frost Resistence.” Cement Wapno Beton, 20(2), 72-78. 
Bodnárová, L., Jarolím, T., Válek, J., Brozovský, J., and Hela, R. (2014). "Selected Properties of Cementitous Composites with Portland Cements and Blended Portland Cements in Extreme Conditions." Applied Mechanics and Materials, 507, 443-448.

CSN EN 12390-3: Testing of hardened concrete - Part 3: Compressive strength, (2002).

CSN EN 12390-5: Testing of hardened concrete - Part5: Flexural strength, (2009).

CSN EN 7313 26: Resistance of cement concrete surface to water and defrosting chemicals (1985).

Drdácký, M., Fratini, F., Frankeová, D., and Slížková, Z. (2013). "The Roman Mortars Used in the Construction of the Ponte di Augusto (Narni, Italy): A comprehensive assessment." Construction and Building Materials, 38, 1117-1128.

Feng, N.Q., Peng, G. F. (2005). "Applications of Natural Zeolite to Construction and Building Materials in China." Construction and Building Materials, 19, 579-584.

Holčapek, O., Vogel, F., Vavřiník, T., Keppert, M. (2014). "Time Progress of Compressive Strength of High Performance Concrete." Applied Mechanics and Materials, 486, 167-172.

Kolář, K., Litoš, J., Bažantová, Z., and Reiterman, P. (2016). "Measurement of Volume Changes of High Performance Cement Based Composites." Applied Mechanics and Materials, 827, 328-331.

Kot’átková, J., Čáchová, M., Vejmelková, E., Reiterman, P. (2015). “Mechanical and Thermal Properties of HSC with Fine Natural Pozzolana as SCM." Materials Science Forum, 824, 167-171.

Kotátková, J., Koňáková, D., Vejmelková, E., Reiterman, P., Siddiqur, J. A. (2015). "Mechanical and Water Transport Properties of HSC with Different SCMs." Materials Science Forum, 824, 105-110.

Máca, P., Jandeková, D., and Konvalinka, P. (2014). "The influence of Metakaolin Addition on the Scaling of Concrete due to Frost Action." Cement Wapno Beton, 19 1-7.

Pavlík, Z., Keppert, M., Pavlíková, M., Žumár, J., Fořt, J., and Černý, R., (2014). "Mechanical, Hygric, and Durability Properties of Cement Mortar with MSWI Bottom Ash as Partial Silica Sand Replacement." Cement Wapno Beton, 19, 67-80.

Reiterman, P., Jogl, M., Baumelt, V., Seifrt, J. (2014). "Development and Mix Design of HPC and UHPFRC." Advanced Materials Research, 982, 130-135.

Reiterman, P., Jogl, M., Konvalinka, P. (2015). "Scaling Resistance of Special High Performance Composites with Burnt Clay Additive." WIT Transactions on Modelling and Simulation, 59, 325-332.

Reiterman, P., Holcapek, O., Jogl, M., Jandekova, D., Konvalinka, P. (2015). "Long-term Resistance of HPC to Action of Deicing Salts.” AIP Conference Proceedings, 1648, 1-4.

Reiterman, P., Keppert, M., Čáchová, M., Holčapek, O., Vogel, F., Kolář, K., and Konvalinka, P. (2014). "Permeability and Basic Physical Properties of Concrete with Metakaolin Addition." Applied Mechanics and Materials, 486, 313-318. 
Sabet, F.A.,. Libre ,N.A, Shekarchi, M. (2013). "Mechanical and Durability Properties of Self Consolidating High Performance Concrete Incorporating Natural Zeolite, Silica Fume and Fly Ash.” Construction and Building Materials, 44, 175.

Sovják, R., Vavřiník, T., Máca, P., Zatloukal, J., Konvalinka, P., Song, Y. (2013). "Experimental Investigation of Ultra-high Performance Fiber Reinforced Concrete Slabs Subjected to Deformable Projectile Impact.” Procedia Engineering, 65, 120-125.

Tydlitát, V., Zákoutský, J., and Černý, R. (2014). "Early-stage Hydration Heat Development in Blended Cements Containing Natural Zeolite Studied by Isothermal Calorimetry.” Thermochimica Acta, 582(1) 53-58.

Valipour, Pargar, M., F., Shekarchi, M., Khani, S. (2013). "Comparing a Natural Pozzolan, Zeolite, to Metakaolin and Silica Fume in Terms of Their Effect on the Durability Characteristics of Concrete: a laboratory study." Construction and Building Materials, 41, 879. 